\title{
Integrasi Program Pencegahan HIV/AIDS melalui Transmisi Seksual ke dalam Sistim Kesehatan di Kota Kupang
}

\author{
Amelya Betsalonia Sir ${ }^{1}$ \\ ${ }^{1}$ Fakultas Kesehatan Masyarakat Universitas Nusa Cendana
}

\section{ABSTRACT}

Background: HIV and AIDS prevention efforts in Indonesia could not be denied that it is still influenced by global health initiatives. As global initiatives continue to decline, efforts to integrate HIV and AIDS programs into the framework of the national health system are both challenges and hopes for achieving program effectiveness and sustainability. This study aims to explore how far the integration of HIV transmission program through sexual transmission into the health system contributes to the effectiveness of programs at the Kupang City level.

Method: The method used in this research is qualitative analysis with case study design as an effort to understand more deeply the relationship between the integration and effectiveness of AIDS prevention program. In this study the 'case' chosen was HIV prevention programs through sexual transmission for Female Sex Workers.

Results: The results of the study showed that in the prevention of HIV transmission programs through sexual transmission as many as five sub-systems of health were partially integrated, including sub-systems of management and regulation, health financing, human resource management, provision of pharmaceuticals and medical devices and sub-systems for community participation management, while the strategic information sub sub-system is not integrated in the health system. The integration of some sub-systems into the health system does not contribute to the effectiveness of the program. Therefore, it was necessary to strengthen each sub-systim, especially in regions ranging from regulation, planning and budget including human resources to increase regional independence and not rely on foreign funds for the implementation of HIV prevention programs through sexual transmission, besides that it also increases collaboration with stakeholders.

Correspondence

Amelyasir23@gmail.com

\section{Article History}

Received 10 July 2019

Revised 02 August 2019

Accepted 14 January 2020

Available Online 6 March 2020

Keywords

Integration program

HIV AIDS

Health system

DOI

10.14710./jpki.15.1.1-8

\section{PENDAHULUAN}

Upaya penanggulangan AIDS di Indonesia tidak bisa dilepaskan dari inisiatif kesehatan global yang dilakukan melalui berbagai skema program dan pendanaan seperti Global Fund, bantuan pemerintah Amerika dan Australia melalui USAID dan DFAT. Keberadaan inisitiaf kesehatan global di Indonesia sejak dari awal permasalahan AIDS di Indonesia terbukti telah mampu meningkatkan pendanaan program dan sebagai konsekuensinya, mampu meningkatkan cakupan layanan terkait dengan HIV dan AIDS. Meski pembiayaan dari inisiatif global ini cenderung menurun dari tahun ke tahun tetapi saat ini, pembiayaan untuk penanggulangan AIDS masih bergantung dari hibah bilateral maupun multilateral karena dana pemerintah masih berkisar $40 \%$ dari total pembiayaan. ${ }^{1}$ Peran inisiatif kesehatan global yang sedemikian besar dalam penanggulangan AIDS di negara-negara berkembang ini telah memunculkan berbagai konsekunsi baik positif maupun negatif terhadap sistim kesehatan. ${ }^{2,3}$
Berbagai studi tersebut telah mendokumentasikan konsekuensi negatif terhadap sistim kesehatan seperti berkembangnya sistim ganda yaitu sistim penanggulangan HIV dan AIDS dan sistim kesehatan pada umumnya, lemahnya insentif dari sistim kesehatan untuk mendukung upaya penanggulangan AIDS dan terbatasnya integrasi layanan HIV dan AIDS dengan layanan kesehatan yang lain. Demikian pula, koordinasi berbagai upaya kesehatan dengan mengembangkan sistim perencanaan, koordinasi dan monitoring yang terpisah dari upaya kesehatan lain. Demikian juga ada kekhawatiran bahwa situasi ini akan memperburuk sistim kesehatan karena akan menggerus sumber daya yang tersedia untuk penanggulangan AIDS.

Pada sisi lain, sejumlah penelitian telah menunjukkan bahwa strategi yang berpotensi untuk meningkatkan efektivitas dan menjamin keberlanjutan intervensi tersebut setelah berakhirnya dukungan dana dan teknis dari lembaga donor adalah dengan mengintegrasikan intervensi spesifik tersebut ke dalam sistim kesehatan. ${ }^{4-6}$ Pentingnya integrasi 
ditunjukkan dengan potensi dalam mengurangi fragmentasi, menghapus tumpang tindih dengan menggabungkan pendanaan, meningkatkan sumber daya dan usaha secara signifikan dan menyatukan berbagai keahlian. ${ }^{2}$ Secara singkat berbagai penelitian tersebut menunjukkan bahwa tingkat integrasi yang lebih tinggi akan mengarahkan kemampuan sistim kesehatan untuk memperbaiki status kesehatan dan kepuasan pemanfaat yang dilayani oleh intervensi tersebut.

Konsep integrasi dalam operasionalisasi didefinisikan secara berbeda-beda oleh para peneliti sesuai dengan konteks penelitiannya tetapi secara umum menunjuk pada pengaturan secara organisasional dan manajemen yang ditujukan untuk membangun kerja sama, kemitraan, layanan yang berkelanjutan dan terkoordinasi, penyesuaian, jaringan atau koneksitas. $^{6,7}$ Meski telah ada berbagai bukti yang menunjukkan bahwa integrasi secara bermakna memiliki keterkaitan dengan meningkatnya kinerja dari intervensi spesifik, tetapi hingga saat ini belum ada kesimpulan yang bulat tentang dampak integrasi sebuah intervensi spesifik ke dalam sistim kesehatan terhadap status kesehatan masyarakat karena masih terbatasnya penelitian yang mengkaji isu tersebut dan juga terbatasnya metodologi yang memadai untuk menentukan hubungan tersebut. ${ }^{4,7}$

Adanya perdebatan tentang kemungkinan dampak negatif dan positif dari integrasi intervensi spesifik seperti penanggulangan HIV yang diinisiasi oleh inisiatif kesehatan global ke dalam sistim kesehatan, telah memunculkan berbagai rekomendasi bagi penyedia dana dan pemerintah untuk memperkuat sistim kesehatan melalui upaya untuk memaksimalkan integrasi intervensi spesifik ke dalam sistim kesehatan. ${ }^{2,4,7}$ Dalam permasalahan HIV dan AIDS, permasalahan integrasi ini bukan merupakan hal yang mudah dilakukan karena melibatkan banyak pemain (dan kepentingan), infrastruktur, kebijakan dan sumber daya di tingkat sistim dan program. Integrasi penanggulangan AIDS ke dalam sistim kesehatan secara konseptual akan memiliki konsekuensi terhadap meningkatknya efektivitas layanan HIV dan AIDS dengan memaksimalkan sumber daya dan infrastruktur yang tersedia. ${ }^{8}$

Dengan demikian, isu efektivitas harus menjadi perhatian utama di dalam melihat seberapa jauh integrasi penanggulangan AIDS ke dalam sistim kesehatan karena AIDS merupakan isu kesehatan yang kompleks dan membutuhkan mobilisasi sumber daya yang besar dan menyerapnya dengan besar pula. Selain penting untuk mengukur tingkat efektivitas program, penting juga dilakukan pengukuran terhadap berbagai faktor yang mempengaruhi tingkat efektivitas program penanggulangan HIV dan AIDS, termasuk PMTS.

Upaya penanggulangan HIV dan AIDS di Kota Kupang masih belum mendapat perhatian serius dari pemerintah daerah. Jumlah kasus tahun 2014 mengalami peningkatan dibanding tahun 2013 sesuai data dari Dinas Kesehatan Kota Kupang Tahun 2014. ${ }^{9}$ Jumlah kasus HIV dan AIDS tahun 2013 tercatat 550 kasus, terus meningkat pada tahun 2014 yang sudah mencapai 630 kasus, atau terjadi penambahan 80 kasus $(14,55 \%)$ dari tahun $2013 .{ }^{10}$ Kasus terbanyak pada kelompok usia produktif yakni 25-34 tahun, sedangkan berdasarkan perkembangan penyakit HIV dan AIDS setiap tahunnya ternyata pada tahun 2014 jumlah kasus paling banyak ditemukan 121 kasus baru dibandingkan dengan tahun-tahun sebelumnya. ${ }^{11}$ Selain itu, bila dibandingkan jumlah kasus HIV dan AIDS dari tahun 2010 yang hanya berjumlah 110 kasus namun sampai dengan tahun 2014 telah mencapai 630 kasus, hal ini menunjukan bahwa perkembangan kasus ini begitu cepat. Upaya pencegahan perlu segera dilakukan agar tidak terjadi penularan yang lebih banyak lagi kepada masyarakat maupun pada kelompok populasi beresiko. Salah satu upaya pencegahannya yaitu dengan program Pencegahan Melalui Transmisi Seksual (PMTS) pada kelompok Wanita Pekerja Seks (WPS) Namun, program ini belum berjalan optimal karena membutuhkan dukungan stakeholder terkait, baik berupa kebijakan dan dukungan dana program, agar upaya pencegahan dapat direalisasikan. Penilaian integrasi program PMTS dalam kerangka sistim kesehatan daerah dengan efektifitas program HIV dan AIDS di Kota Kupang.

Tujuan dari integrasi respon HIV dan AIDS ke dalam sistim kesehatan pada dasarnya adalah untuk memperkuat efektivitas, efisiensi dan pemerataan yang berkeadilan dari respon tersebut dan sekaligus sistim kesehatannya. Sayangnya hingga saat ini masih terbatas berbagai penelitian yang menyediakan bukti atas manfaat integrasi respon HIV dan AIDS ke dalam sistim kesehatan. Berdasarkan hal tersebut, maka penelitian ini bermaksud untuk menentukan secara sistimatik pengaruh integrasi respon HIV dan AIDS ke dalam sistim kesehatan terhadap efektivitas program dan sekaligus mengidentifikasi mekanisme yang memungkinkan terjadinya pengaruh integrasi atas efektivitas program penanggulangan AIDS.

Tujuan umum dari penelitian ini adalah untuk melihat secara sistimatik kontribusi integrasi respon HIV dan AIDS ke dalam sistim kesehatan terhadap efektivitas respon AIDS pada tingkat Kota Kupang dan mengidentifikasi tentang mekanisme yang memungkinkan integrasi tersebut bisa berkontribusi terhadap efektivitas respon HIV dan AIDS.

Secara spesifik tujuan penelitian ini adalah: Untuk menggali kontribusi integrasi sistim manajemen dan regulasi, sistim penyediaan kefarmasian dan alat kesehatan,sistim pengelolaan smber daya manusia, sistim informasi kesehatan strategis dan sistim pengelolaan partisipasi masyarakat dalam penanggulangan HIV dan AIDS ke dalam sistim kesehatan terhadap efektivitas intervensi pencegahan dan perawatan dan dukungan HIV dan AIDS. 


\section{METODE}

Penelitian ini merupakan penelitian kualitatif yang menggunakan desain studi kasus sebagai upaya untuk memahami lebih dalam hubungan antara integrasi dan efektivitas penanggulangan HIV dan AIDS. Dalam penelitian ini, 'kasus' yang dipilih adalah PMTS pada Wanita Pekerja Seks (WPS) yang merupakan intervensi spesifik di dalam penanggulangan HIV dan AIDS di tingkat Kota Kupang.

Data primer dan sekunder dikumpulkan dalam penelitian ini. Pengumpulan data dilakukan melalui wawancara dengan informan kunci yang telah ditentukan di tingkat Kota Kupang dengan menggunakan panduan wawancara yang telah dikembangkan oleh tim PKMK (Pusat Kebijakan dan Manajemen Kesehatan) Fakultas Kedokteran UGM. ${ }^{12}$ Data primer mencakup:

a. Konteks kebijakan respon HIV dan AIDS di suatu wilayah yang mencakup konteks politik, ekonomi, hukum dan regulasi serta permasalahan kesehatan.

b. Pelaksanaan fungsi-fungsi sistim kesehatan (manajemen dan regulasi, SDM, pembiayaan, penyediaan farmasi dan alkes, informasi strategis, partisipasi masyarakat dan penyediaan layanan) di tingkat sistim kesehatan daerah dan tingkat program HIV dan AIDS.

Data sekunder dikumpulkan dari berbagai data yang digunakan untuk mengukur efektivitas program HIV dan AIDS yang mencakup:

a. Data Kontekstual (kebijakan pemda, anggaran daerah, dokumen perencanaan/laporan kinerja daerah, situasi kesehatan, data epidemiologi, dan lain-lain).

b. Data pendukung pelaksanaan fungsi-fungsi sistim kesehatan (Manajemen dan regulasi, SDM, pembiayaan, penyediaan farmasi dan alkes, informasi strategis, partisipasi masyarakat dan penyediaan layanan).

c. Indikator keluaran, hasil dan dampak program yang terkait dengan jenis intervensi PMTS pada WPS di Kota Kupang dan data kinerja penanggulangan AIDS secara keseluruhan.

Penelitian dilakukan di wilayah Kota Kupang dilaksanakan pada bulan Oktober 2015 - Februari 2016.

Informan kunci dalam penelitian ini dipilih secara purposive karena pengetahuan mereka tentang sistim kesehatan dan program HIV dan AIDS yang terdiri atas berbagai organisasi, posisi, dan spesialis pada sistim kesehatan dan program HIV dan AIDS. Mereka terdiri dari perwakilan dari BAPPEDA, Dinas Kesehatan Kota Kupang, Komisi Penanggulangan AIDS Kota Kupang, Puskesmas Alak dan Puskesmas Bakunase, Rumah Sakit rujukan, LSM yang melaksanakan program HIV dan AIDS yaitu Yayasan Tanpa Batas (YTB) dan LSM Flobamora Support bersama Kelompok Dampingan Sebaya (KDS) Sasando plus dan
KDS Perjuangan serta populasi yang terdampak oleh HIV dan AIDS terdiri atas WPS dan LGBT.

Data yang telah dikumpulkan melalui wawancara lalu ditranskip secara verbatim yang kemudian dikode dan dianalisis. Analisis data menggunakan Framework Approach yang merupakan metode analisis data yang biasa digunakan dalam penelitian kebijakan kesehatan dan sosial dimana tujuan dari penelitian telah ditentukan sebelumnya. ${ }^{7}$ Kerangka kerja ini juga secara khusus sesuai dengan pengolahan data besar dengan waktu yang terbatas. Tahapan dalam kerangka kerja ini adalah (1) memetakan kerangka kerja tematik(2) membuat indeks (3) membuat diagram (charting) (4) memetakan dan menafsirkan.

\section{HASIL DAN PEMBAHASAN \\ Analisis Kontekstual}

Berdasarkan analisis kontekstual, diketahui kebijakan politik pemerintah daerah terhadap penanggulangan HIV dan AIDS termasuk PMTS sudah cukup baik. Hal ini ditunjukkan dengan telah masuk isu pencegahan dan penanggulangan HIV dan AIDS ke dalam RPJMD tahun 2013 - 2017 yang secara otomatis berdampak terhadap alokasi anggaran untuk pencegahan dan penanggulangan HIV dan AIDS, termasuk PMTS. Selain itu, ditunjang dengan dukungan peraturan daerah yang mengatur tentang pencegahan dan penanggulangan HIV dan AIDS dalam bentuk peraturan daerah (Perda) dan Peraturan Walikota (Perwali) dan dipakai sebagai acuan dalam pelaksanaan pencegahan dan penanggulangan HIV dan AIDS di Kota Kupang.

Berdasarkan Konteks ekonomi terkait pencegahan dan penanggulangan HIV dan AIDS termasuk PMTS, menunjukkan bahwa komitmen pemerintah daerah yang cukup baik terhadap upaya penanggulangan HIV dan AIDS dengan mengalokasikan anggaran yang terus mengalami peningkatan. APBD Kota Kupang Tahun 2014 mengalokasikan anggaran sebesar 6-7\% dari total anggaran untuk kesehatan termasuk program PMTS, walaupun belum mencapai $10 \%$ dari total anggaran untuk kesehatan. Anggaran untuk pencegahan dan penanggulangan HIV dan AIDS menyebar di Dinas Kesehatan Kota Kupang, Komisi Penanggulangan AIDS (KPA) Kota Kupang dan 6 Puskesmas di Kota Kupang. Selain itu adanya LSM yang ikut mendukung seperti Yayasan Tanpa Batas.

Aspek hukum melalui peraturan dan kebijakan semakin memperkuat pelaksanaan pembangunan kesehatan. Kota Kupang tidak memiliki hukum dan peraturan yang menghambat akses terhadap layanan kesehatan baik secara umum maupun layanan terkait HIV dan AIDS untuk masyarakat umum termasuk kelompok populasi berisiko.

Sedangkan untuk konteks permasalahan kesehatan di Kota Kupang mengalami perubahan dari tahun ke tahun sesuai dengan pola perkembangan dan kebutuhan 
masyarakat. Penyakit HIV dan AIDS sebagai salah satu penyakit prioritas pemerintah daerah sudah masuk dalam RPJMD tahun 2013-2017. ${ }^{13}$ Ini semakin menunjukkan adanya komitmen dan dukungan pemerintah daerah baik dari segi anggaran maupun kebijakan daerah terhadap upaya pencegahan dan penanggulangan HIV dan AIDS, termasuk PMTS. Walaupun tidak secara spesifik disebutkan.

\section{Analisis Tingkat Integrasi Sub Sistim Kesehatan}

\section{Manajemen dan Regulasi}

Pelaksanaan program PMTS telah dilaksanakan mulai dari tingkat pelayanan dasar atau tingkat Puskesmas. Pelaksanaan PMTS di Puskesmas telah menjadi bagian dari pelayanan IMS dan masuk dalam tata kelola program IMS dan HIV di tingkat Dinas Kesehatan Kota. Layanan IMS juga telah menjadi layanan wajib di Puskesmas. Berdasarkan hasil wawancara dengan Kepala Bidang Pelayanan Kesehatan (Yankes) menyatakan bahwa kegiatan PMTS yang dilaksanakan di Dinas Kesehatan telah terintegrasi dengan program-program lain yang ada seperti dengan promosi kesehatan, kesehatan ibu dan anak. Bentuk kegiatannya seperti penyuluhan IMS dan HIV, penyaringan dan pengobatan ibu hamil dengan keluhan keputihan, layanan pemeriksaan dan pengobatan IMS, mobile IMS yang bekerjasama dengan KPA dan rujukan ke RSU. KPA juga sebagai koordinator program PMTS dalam pelaksanaannya melakukan sosialisasi, pertemuan rutin baik dengan stakeholder, mitra dan kelompok populasi kunci (WPS) serta pembentukan Warga Peduli AIDS (WPA).

Perencanaan dan anggaran program PMTS, Sekretaris KPA menyatakan KPA memiliki kewenangan untuk menyusun program HIV dan AIDS secara umum dan bukan spesifik PMTS saja. Tidak ada pengaruh dari pusat dalam hal ini Kemenkes, KPAN dan lembaga donor dalam penentuan target maupun besarnya dana program pelaksanaan program dilakukan sesuai dengan kemampuan SDM dari KPA sendiri. Hal ini seperti diungkapkan oleh salah satu informan sebagai berikut:

"Kami susun sendiri kan, jadi paling pemerintah hanya tahu anggaran berapa plafon, kita perjuangkan, macam tahun depan saya minta tambah, terutama untuk dukungan 5 juta per WPA sekarang kan kalau kita tidak dikasih dana mereka diam ditempat" (Wawancara dengan Sekretaris KPA Kota Kupang)

Perencanaan program PMTS melibatkan stakeholder terkait mengingat pembagian pelaksanaan 4 pilar PMTS yaitu Dinkes Kota, Puskesmas dan LMS YTB bersama pokja PMTS yang telah terbentuk di lokasi. Beberapa kegiatan yang masuk dalam perencanaan KPA terkait PMTS yaitu sosialisasi dan penyuluhan, mobile VCT dan pembentukan Warga Peduli AIDS (WPA). KPA juga memiliki kewenangan untuk menyusun anggaran terkait program
PMTS, yang sumber dananya berasal dari pemerintah dan dana donor (GF). Sedangkan perencanaan dan penganggaran program PMTS di Dinas Kesehatan menjadi bagian yang tidak terpisahkan dari perencanaan dan penganggaran progam IMS dan HIV.

Akuntabilitas dan daya tanggap untuk program PMTS, pelaksanaan kegiatan lebih banyak melibatkan kelompok populasi kunci baik itu WPS, Waria, penasun dan kelompok populasi lainnya, misalnya dalam pembentukan WPA dimana mereka sebagai narasumber, pendataan hotspot, sosialisasi dan mobile VCT, sero survey dan pertemuan rutin. Namun mereka tidak terlibat dalam perencanaan program dan anggaran maupun evaluasi program.

\section{Pembiayaan Kesehatan}

Sumber dana untuk penanggulangan HIV dan AIDS cukup beragam dan tersebar dibeberapa instansi. KPA memiliki sumber dana paling besar dari APBD sebesar 600 Juta dan GF sebesar 154 Juta yang penggunaannya tidak terbatas pada program PMTS. Dinkes juga hanya mengelola dana APBD dan GF untuk program HIV dan AIDS. Menurut Kasie P2 Dinkes, jika ada program yang sudah masuk dalam pembiayaan GF, maka Dinkes tidak akan memasukkan lagi dalam perencanaan anggaran program APBD. Demikian halnya dengan KPA, seperti kegiatan sero survey tahun lalu dananya bersumber dari KPA, maka Dinkes tidak mengalokasikan lagi, tinggal berkoordinasi dengan KPA untuk pelaksanaannya. Hal ini seperti diungkapkan oleh salah satu informan sebagai berikut:

"Itu biasanya kalau sudah ada kegiatan-kegiatan yang sudah ada di GF kita tidak masukan lagi di APBD. Misalkan kayak mobile VCT kan, kalau mobile VCT kan dianggarkan di GF, di APBD itu biasanya kita rencanakan, tapi kalau sudah ada di GF kita tidak di akomodir biasanya, supaya tidak terjadi pendobelan" (wawancara dengan Kasie P2 Dinkes Kota Kupang)

Untuk program PMTS, data perencanaan dan keuangan Dinas Kesehatan Kota Kupang untuk tahun 2014 menunjukkan proporsi dana dari luar APBD lebih kecil dibanding dengan dana dari APBD. Alokasi dana GF untuk Dinkes sebesar 29 Juta dan itu tidak saja untuk program HIV, tapi termasuk TB dan malaria sehingga proporsinya lebih kecil. Sedangkan dana GF untuk KPA Kota tahun 2014 sebesar 156 Juta, lebih kecil dibandingkan dana dari APBD yaitu 600 Juta. Sedangkan untuk proporsi paling besar pada pencegahan termasuk program PMTS., ${ }^{9,14}$ Berdasarkan informasi PM LSM Flobamora Support diketahui ada dana penanggulangan HIV dan AIDS yang telah dianggarkan pemerintah melalui KPA Propinsi yang dapat diakses oleh LSM sebesar 200 Juta berupa bantuan sosial. Regulasinya jika LSM ingin mengakses dana tersebut perlu membuat usulan proposal kegiatan, namun tidak semua proposal 
kegiatan diterima karena KPA akan memberikan penilaian dan pertimbangan baik program dan anggarannya. Hal ini seperti hasil kutipan wawancara dengan Sekretaris KPA sebagai berikut:

"Iya untuk kegiatan-kegiatan LSM ada dana 200 juta silahkan ajukan proposal" (Wawancara dengan Program Manajer LSM Flobamora Support)

"Bertanggung jawab, jadi kan begini, mereka buat TOR, mereka kan diskusi dulu, terus mereka ajukan TOR, tanda tangan, saya setujui, dana cair, tidak terlalu berbelitbelit" (Wawancara dengan Sekretaris KPA Kota Kupang)

Pengaruh Kemenkes dan KPAN dalam menentukan distribusi pendanaan dan alokasi kegiatan terkait program PMTS, menurut KPA kecil sebab pendanaan dari pusat juga kecil, selama ini bantuan dari pusat dalam bentuk distribusi kondom dan pelicin saja. Berbeda halnya dengan Puskesmas, dimana GF memiliki pengaruh yang cukup besar karena dana operasional di Puskesmas untuk tatalaksana IMS termasuk HIV dan rujukan menggunakan dana dari GF.

Sedangkan untuk mekanisme pembayaran layanan PMTS yang dijamin oleh JKN diantaranya termasuk pemeriksaan dan obat IMS, pemeriksaan CD4. Jenis layanan ini dapat diakses di Puskesmas oleh semua masyarakat termasuk kelompok populasi kunci (WPS) selama mereka memiliki kartu BPJS atau Jamkesda.

\section{Sumber Daya Manusia Kesehatan}

Secara khusus untuk program HIV dan AIDS termasuk PMTS, bahwa tersedia tenaga kesehatan disetiap tingkatan layanan. Walaupun tidak ada rekrutmen khusus terkait layanan IMS dan HIV baik di Puskesmas maupun di klinik VCT RSU. Tenakes yang melayani adalah tenakes yang ada di instansi dan mendapat tugas tambahan. Belum ada kebijakan khusus untuk pengelolaan SDM yang terlibat dalam program PMTS yang berasal dari sektor nonkesehatan seperti LSM. Namun berdasarkan informandiketahui bahwa ada kegiatan-kegiatan yang juga melibatkan tenaga LSM seperti mobile VCT dan kegiatan Warga Peduli AIDS (WPA), dimana mereka terlibat sebagai pemateri. Demikian juga di Puskesmas, jika ada pasien yang dirujuk ke klinik VCT RSU maka pihak Puskesmas akan menghubungi petugas LSM untuk membantu pasien dalam pemeriksaan VCT, walaupun pengaturannya tidak secara formal.

Hal ini menunjukkan dimensi kebijakan dan sistim manajemen SDM terkait PMTS baik yang ada di fasilitas layanan kesehatan maupun SDM non kesehatan tidak secara khusus menjalankan program PMTS, namun menjalankan tugas ganda baik secara struktural dan fungsional yang dibebankan instansi Selain itu juga karena belum adanya regulasi yang jelas untuk pengaturan SDM kesehatan yang bekerja pada program PMTS maupun regulasi kerjasama
SDM kesehatan dengan non kesehatan sebagai upaya integrasi dan koordinasi program PMTS, sehingga kerjasama yang ada selama ini lebih situasional atau tergantung dari jenis kegiatan dan tidak ada panduan atau petunjuk teknis pelaksanaan di lapangan.

Sedangkan untuk pembiayaan SDM program PMTS berasal dari dana insentif donor, baik di Puskesmas untuk penatalaksanaan IMS dan mobile klinik, petugas LSM untuk penjangkauan dan membantu rujukan pasien ke klinik VCT. Insentif ini dapat menjadi stimulus dalam menunjang pelaksanaan dan keberhasilan program PMTS, namun dapat juga menjadi hambatan. Mengingat keberlangsungan donor di daerah akan segera berakhir, sedangkan daerah dalam hal ini Dinas Kesehatan belum mempersiapkan segala konsekuensi yang akan terjadi jika MPI sudah tidak lagi ada dan mendukung program PMTS di daerah.

Adanya rotasi dan mutasi tenakes program HIV dan termasuk PMTS baik di Puskesmas dan rumah sakit sangat berdampak bagi kualitas layanan yang diberikan. Hal ini seperti diungkap oleh salah satu informan sebagai berikut:

"Pergantian, kalau pindah apa kita hanya bisa ini, sebetulnya waktu di pelatihan dari Kementerian itu kan Global Fund juga sudah ditulis di situ, tidak boleh pindah selama sekian tahun. Iya, tapi kenyataannya kan orang juga tidak tega, mau pindah dimana" (Wawancara dengan penanggung jawab klinik VCT RSUD)

\section{Penyediaan Farmasi dan Alat Kesehatan}

Mekanisme pengadaan obat-obatan dan alat kesehatan di Kota Kupang dilakukan berdasarkan Renja (Rencana Kerja) yang disesuaikan dengan perencanaan kebutuhan di Puskesmas. Sedangkan perencanaan dan pengadaan obatobatan dan alkes terkait program PMTS, secara umum tidak berbeda jauh. Dinas Kesehatan mengusulkan obat-obatan antibiotik untuk IMS, berdasarkan usulan Puskesmas dengan dasar acuan adalah estimasi kasus IMS atau data pasien serta perhitungan kebutuhan obat. Sedangkan alat kesehatan yang terkait seperti kondom, pelicin, jarum suntik dan KIE tidak menjadi bagian perencanaan dan pengadaan Dinkes Kota karena sudah di support dari donor (Global Fund) melalui KPA, ataupun melalui Dinas Kesehatan Propinsi untuk reagen. Tidak ada regulasi khusus yang mengatur sehingga untuk reagen alurnya berbeda dengan perencanan dan pengadaan alkes secara umum. Hal ini seperti diungkapkan oleh salah satu informan sebagai berikut:

"Kalau reagen mungkin lebih ke klinik VCT ya, kalau kita di puskesmas kan belum ada VCT jadi belum ada. Biasanya reagen yang kendalanya di VCT. Itu biasanya mereka mintanya ke propinsi" (Wawancara dengan Kasie P2 Dinkes Kota)

Distribusi obat dan alat kesehatan secara umum melalui gudang farmasi untuk selanjutnya didstribusi ke 
fasilitas pelayanan kesehatan seperti Puskesmas dan Pustu sesuai permintaan dengan memperhatikan masa berlaku obat, demkian halnya untuk obat IMS. Namun untuk reagen disediakan oleh Pusat (Kementrian Kesehatan) dan didistribusi ke Dinas Kesehatan Propinsi melalui Povabelkes untuk selanjutnya didistribusi ke ke Klinik VCT, dan RS yang biaya distribusinya ditanggung oleh pusat. Distribusi kondom dan pelicin menjadi tanggung jawab KPA, dimana KPAN mendistribusi ke KPA Kota sebagai gudang kondom tingkat Kota, kemudian didistribusi ke outlet-outlet kondom sebanyak 28 outlet termasuk Dinkes dan Puskesmas.

Hambatan untuk dimensi regulasi penyediaan, penyimpanan, diagnostik dan terapi untuk program PMTS, antara lain belum ada aturan atau regulasi yang mengatur secara jelas tentang penyediaan, penyimpanan obat dan alat kesehatan terkait PMTS, mekanisme yang dibangun hanya berdasarkan kesepakatan antar instansi secara informal dan situasional.

Sumber daya untuk untuk program PMTS, obat dan alkes dianggarkan oleh Dinkes Kota diantaranya antibiotic untuk IMS dan jarum suntik, beberapa jenis obat Infeksi Oportunistik (IO) dan reagen berasal dari Dinas Kesehatan Propinsi.Sedangkan untuk KIE, kondom dan pelicin dibiayai oleh pemerintah pusat melalui KPAN yang pendanaannya disupport dari GF.

\section{Informasi Strategis}

Data program terkait PMTS yang dikumpulkan baik dari Puskesmas, RSU maupun LSM. Data -data ini memang tidak semua terpusat di Dinkes Kota, ada yang pelaporannya langsung ke KPA atau ke lembaga donor (GF), seperti data penjangkauan kelompok populasi kunci yang dilakukan oleh LSM dilaporkan ke lembaga donor, sedangkan ke KPA atau ke Dinkes tidak rutin dilakukan, tergantung permintaan.

Mekanisme pelaporan dilakukan berjenjang dari layanan seperti Pustu dan Puskesmas ke Dinkes Kota. Waktu pengumpulan, ada yang mingguan, bulanan, trimester dan tahunan. Pola yang berbeda diterapkan untuk sero survey dan data estimasi, dimana pelaksana dan pengumpulan data dilakukan langsung oleh tenakes dari Dinkes yang berkoordinasi dengan KPA Kota. Serro survey dilakukan 2 kali dalam setahun. Untuk data terkait PMTS sendiri memang ditemukan pola-pola yang berbeda dengan sistim pencatatan dan pelaporan secara umum dalam sistim kesehatan.

Berdasarkan sistim informasi yang digunakan untuk pengumpulan dan pelaporan memang berbeda-beda, untuk LSM menggunakan SINU, sedangkan untuk Dinkes dan RSU menggunakan SIHA. Baru 4 Puskesmas di Kota Kupang yang menggunakan SIHA untuk pencatatan dan pelaporan, sedangkan 6 Puskesmas lainnya belum. Selain SIHA, saat ini juga sudah dikembangkan SIKDA untuk tingkat Kota Kupang, sehingga untuk sistim pencatatan dan pelaporan Dinkes menggunakan 2 sistim ini.
Data program terkait PMTS diantaranya data layanan seperti rekapan data kasus IMS dari Puskesmas dikumpulkan ke Dinkes Kota, sedangkan data penjangkauan dan distribusi kondom dari KPA dan LSM tidak menjadi bagian pengumpulan data ke Dinkes Kota, karena LSM tidak berkewajiban untuk memberikan data ke Dinkes maupun KPA, namun sesuai dengan permintaan dan kebutuhan.Walaupun berdasarkan hasil penelitian ditemukan ada perbedaan data yang dihasilkan oleh Dinkes dengan data LSM, misalnya untuk data rujukan LSM ke layanan VCT. Perbedaan data rujukan ke klinik VCT RSU ini dikarenakan ada 2 jenis rujukan yang selama ini dipakai, yang pertama rujukan dari Puskesmas dan rujukan dari LSM. LSM YTB sendiri juga memiliki klinik yang biasanya menjadi rujukan oleh sebagian besar kelompok populasi kunci ${ }^{15}$. Hal ini seperti diungkapkan oleh salah satu informan sebagai berikut:

"Tidak, ketika dinas butuh baru dilaporkan, sebenarnya sih mereka (LSM) harus melapor cuma kadang-kadang mereka susah sekali. Kadang-kadang kita harus telfon dulu” (Wawancara dengan Kasie P2 Dinkes Kota)

\section{Upaya Kesehatan}

Ketersediaan layanan PMTS, makin diperkuat dengan terbentuknya jejaring layanan yang komprehensif dan pembagian tugas; dimana KPA dan LSM fokus ke penyuluhan dan penjangkauan, termasuk distribusi kondom untuk kelompok masyarakat umum maupun kelompok populasi kunci (WPS) serta melakukan mobile klinik Terkait akses layanan PMTS, untuk tatalaksana IMS telah tersedia di setiap Puskesmas yang dapat diakses oleh setiap masyarakat termasuk kelompok populasi beresiko. Namun, berdasarkan informasi, sebagian besar dari kelompok populasi berisiko lebih memilih untuk mengakses layanan pemeriksaan IMS dan VCT di layanan milik klinik LSM YTB atau langsung ke rumah sakit dari pada ke Puskesmas. Hal ini seperti diungkap oleh salah satu informan sebagai berikut:

"Kebetulan yg slama ini saya akses adl melalui YTB dan klo di YTB sendiri mereka ada pelayanan satu atap, mereka sudah ada klinik disitu klinik Venesia,jadi kita semua segala sesuatu semua disitu, nah klo misalkan berdasarkan hasil pemeriksaan VCT \& klo mmg ada teman yg dinyatakan positif, nah dari situ teman-teman akan diarahkan oleh konselor untuk mungkin bs bergabung bersama dengan teman2 dalam 1 populasi kunci misalnya teman2 organisasi Odha mungkin utk bisa masuk dalam KDS" (wawancara dengan salah satu kelompok populasi kunci)

Ada berbagai alasan mereka mengapa lebih memilih mengakses layanan di fasilitas non pemerintah, diantarannya masih adanya stigma dan diskriminasi dari petugas kesehatan di Puskesmas, jika dirujuk maka alur rujukan yang rumit dan berbelit-belit sering menjadi kendala dan aspek 
kenyamanan dengan petugas klinik di LSM Yayasan Tanpa Batas. Hal ini seperti diungkap oleh salah satu informan sebagai berikut:

"Mungkin juga dilihat dari teman-teman punya ketakutan sendiri karena kan mereka berasal dari komunitas apalagi teman-teman transgender, kita punya ketakutan kalau kita pergi untuk mengakses layanan kesehatan takut ada diskriminasi gitu. kalau saya tidak karena saya memang hanya pernah VCT saja dan itu pun saya lakukan di LSM YTB. Saya tidak pernah di luar itu misal di RS atau Puskesmas, kan sekarang sudah ada VCT" (Wawancara dengan salah satu kelompok populasi

Hambatan dalam menerapkan LKB diantaranya kesiapan fasilitas dan tenaga layanan untuk melaksanakan layanan disetiap tingkatan baik itu di Puskesmas, RSU, KPA, Dinkes dan LSM termasuk kelompok dukungan sebaya (KDS). Koordinasi yang masih lemah disetiap layanan ditunjukkan dengan masih rumit dan berbelitbelitnya alur rujukan dan petugas yang terbatas di layanan sehingga sering terjadi penumpukan pasien.

\section{Partisipasi Masyarakat}

Partisipasi masyarakat secara aktif dalam pembangunan kesehatan mutlak diperlukan, karena masyarakat tidak saja menjadi objek namun juga subjek pelayanan kesehatan. Penilaian partisipasi masyarakat dapat terlihat dalam berbagai kegiatan baik perencanan dan pelaksanaan program kesehatan. Salah satunya adalah dengan musrenbang.

Bentuk keterlibatan masyarakat juga ditunjukkan dengan keterlibatan langsung dalam upaya promosi atau hadir dalam sosialisasi, aktif sebagai kader, juga terlibat dalam kegiatan Jumat bersih. Sedangkan terkait akses dana APBD oleh masyarakat, hasil wawancara dengan informan diketahui bahwa dana dapat diakses melalui KPA Propinsi sejumlah 200 Juta berupa dana bansos kepada LSM untuk pengembangan LSM, dengan aturan LSM memasukkan proposal kegiatan. Selain itu, masyarakat umum pun dapat mengakses dana melalui KPAK melalui dana operasional untuk Pembentukan Warga Peduli AIDS (WPA) yang sudah ada disetiap Kelurahan, walaupun jumlahnya tidak terlalu besar menurut Sekretaris KPAK.

Keaktifan populasi kunci (WPS, LSL, Waria) lebih ditunjukkan melalui organisasi-organisasi yang telah terbentuk. Setiap kelompok populasi beresiko juga berkoordinasi dengan LMS YTB dan KPAK. Walaupun keterlibatan dan keaktifan mereka sebatas pada kegiatan sosialisasi dan penyuluhan terkait IMS dan HIV, serta penjangkauan kepada kelompok komunitas mereka baik untuk melakukan pemeriksaan dan penggunaan kondom. Sedangkan untuk kelompok WPS, mereka tidak terlibat aktif karena adanya tuntutan ekonomi, sehingga tidak terlalu banyak yang terlibat dalam kegiatan. Kelompok populasi kunci ini juga sering dilibatkan dalam pertemuan oleh KPA, namun kehadiran mereka hanya sebatas formalitas memenuhi undangan, karena mereka tidak secara langsung dilibatkan dalam perencanaan dan anggaran terkait program PMTS.

\section{SIMPULAN}

Terintegrasinya sebagian sub sistim manajemen dan regulasi, pengelolaan sumber daya manusia, penyediaan kefarmasian dan alat kesehatan, informasi strategis program PMTS dalam sistim kesehatan secara umum, tidak berkontribusi terhadap efektifitas cakupan progam. Sedangkan, terintegrasinya sebagian sub sistim pembiayaan kesehatan dan pengelolaan partisipasi masyarakat program PMTS ke dalam sistim kesehatan, berkontribusi efektif terhadap cakupan program PMTS.

\section{Ucapan Terima Kasih}

Peneliti mengucapkan terimakasih kepada pihak sponsor yaitu Departement of Foreign Affairs and Trade (DFAT) dan Tim Pusat Kebijakan dan Manajemen Kesehatan (PKMK) Fakultas Kedokteran Universitas Gadjah Mada yang telah memberikan kesempatan kepada peneliti dari Universitas Nusa Cendana untuk melakukan penelitian ini dan juga semua informan yang telah terlibat dan berpartisipasi dalam penelitian ini.

\section{KEPUSTAKAAN}

1. Nadjib M, Megraini A, Ishardini L, Rosalina L. National AIDS Spending Assessment 2011-2012. 2013;(December):1-46.

2. Atun R, de Jongh T, Secci F, Ohiri K, Adeyi O. A systematic review of the evidence on integration of targeted health interventions into health systems. Health Policy Plan. 2010 Jan;25(1):1-14.

3. Shakarishvili G, Atun R, Berman P, Hsiao W, Burgess C, Lansang MA. Converging Health Systems Frameworks: Towards A Concepts-to-Actions Roadmap for Health Systems Strengthening in Low and Middle Income Countries. Glob Heal Gov. 2010;III(2):1-17.

4. Kawonga M, Blaauw D, Fonn S. Aligning vertical interventions to health systems: a case study of the HIV monitoring and evaluation system in South Africa. Heal Res Policy Syst. 2012 Dec;10(1):2.

5. Kawonga M, Fonn S, Blaauw D. Administrative integration of vertical HIV monitoring and evaluation into health systems: a case study from South Africa. Glob Health Action. 2013 Jan;6(1):19252.

6. Shigayeva A, Atun R, McKee M, Coker R. Health systems, communicable diseases and integration. Health Policy Plan. 2010 Nov;25(Suppl. 1):i4-20.

7. Coker R, Balen J, Mounier-Jack S, Shigayeva A, Lazarus J V., Rudge JW, et al. A conceptual and 
analytical approach to comparative analysis of country case studies: HIV and TB control programmes and health systems integration. Health Policy Plan. 2010 Nov;25 Suppl 1(Suppl. 1):i21-31.

8. Dudley L, Garner P. Strategies for integrating primary health services in low- and middle-income countries at the point of delivery. Cochrane Database Syst Rev. 2011 Jul;(7):CD003318.

9. Dinas Kesehatan Kota Kupang. Profil Kesehatan Kota Kupang Tahun 2014. 2014.

10. Dinas Kesehatan Kota Kupang. Data IMS Kota Kupang Tahun 2014. 2014.
11. Kemenkes RI. Laporan Kasus HIV dan AIDS Triwulan III Tahun 2014. 2014.

12. Tim PKMK FK UGM. Panduan Operasional Penelitian Studi Kasus Integrasi Respon HIV dan AIDS ke dalam Sistem Kesehatan dan Efektivitas Penanggulangan HIV dan AIDS di daerah. 2015;

13. BAPPEDA Kota Kupang. RPJMD Kota Kupang Tahun 2013-2017. 2013.

14. BAPPEDA Kota Kupang. Rencana Kerja Pemerintah Daerah (RKPD) Kota Kupang Tahun 2014. 2013;

15. YTB Kota Kupang. Data Hasil Capaian Program Penjangkauan Tahun 2014. 2014; 